DOI: $10.21554 / h r r .091810$

\title{
CLINICAL PROTOCOL FOR APHASIA AND APHASIA TEAM
}

\author{
Dragan Stojiljković Čauševac ${ }^{1}$
}

\author{
Professional paper
}

School of Social Work, Belgrade-Department of Speech and Language Pathology

Received: 18.7.2018

Accepted: 24.8.2018

\begin{abstract}
The Clinical Protocol for Aphasia was created on the basis of international scientific research and presented to the professionals in this field at the First Congress of the Speech and Language Pathologists of Serbia. The Protocol, whose character is diagnostic-prognostic, is multidimensional in its structure containing five axes of assessment. Its greatest value is that it aims at realistic goal setting in the rehabilitation therapy of aphasia.Communication is the key to social participation and the objective of the rehabilitation of aphasia is a social goal, i.e., the optimization of communication between aphasia patientand their environment.The imperative of the protocol is interdisciplinarity, so one of the protocol outcomes is the aphasia team. The aphasia team is characterized by interdisciplinarity, functionality, flexibility and dynamism. One of the outcomes of the application of the Clinical Protocol for Aphasia is the choice of treatment: approach to leading disorder, functional approach, and social approach.
\end{abstract}

Key words: aphasia, protocol, aphasia team, treatment

\section{INTRODUCTION}

In an attempt to raise the level of health services to a higher level by exploiting professional resources acquired through a system of continuous education (specializations, master studies, doctoral studies, and technological innovations), patients with communication disorders, disturbances and accompanying cognitive deficits resulting from neurological diseases are provided with better and more efficient treatment. This can be achieved in specialized medical institutions whose main activity is speech pathology such as the Institute for Psychophysiological Disorders and Speech Pathology containing both professional and technical-spatial resources (experts, policlinics, dispensaries and infir- maries), as well as in other centers for the rehabilitation of neurological patients and clinical-hospital centers in Serbia.

The Institute for Psychophysiological Disorders and Speech Pathology has been conducting rehabilitation therapies of aphasia patients for more than two decades. The rehabilitation therapies havebeencarried out within the Department of Aphasia via individual policlinictherapeutic procedures andinfirmary treatment. Individual treatment is continuously performed twice a week by combining speech and cognitive therapy. Therapeutic procedures are conducted by professionals who have mastered skills and knowledge in the field of communication science, neuropsychological techniques and sociotherapy approaches (Čauševac, 2009).

\footnotetext{
${ }^{1}$ Correspodence to:

Dragan Stojiljković Čauševac, School of Social Work, Belgrade-Department of Speech and Language Pathology

E-mail: dragancausevac@yahoo.com
} 
Following the requirements of contemporary science and profession in the field of communication sciences and disorders, and neurocognitive sciences, we have adopted and applied in practice the clinical protocol for aphasia-Multi Axial Aphasia System (MAAS) protocol (Sandt-Koenderman, 2007).

Clinical Protocol for Aphasia (MAAS) was presented to the professional and scientific public at the first Congress of the Speech and Language Pathologists of Serbia (Čauševac \& Oljača, 2012).

We are fully aware of the fact that "protocols" are a reflection of professional and scientific accomplishments in a certain period of time, and are consequently subject to change and innovation obliging professionals to follow them.

\section{The Content of the Clinical Protocol for Aphasia}

"The Multi-axial Aphasia System (MAAS) was developed to structure linguistic, somatic, neuropsychological, psychosocial and socio-economic information on five separate axes, enabling an explicit and interdisciplinary process of clinical decision-making. The objectives of this study were to investigate the potentialities of MAAS in predicting the outcome of cognitive-linguistic treatment" (van de Sandt-Koenderman et al., 2008). MAAS - Multi-axial Aphasia System aims at realistic goal setting in the rehabilitation therapy of aphasia taking into consideration that communication is the key to social participation while the objective of the rehabilitation of aphasia is a social goal, i.e., the optimization of communication between patient and their environment.

The Clinical Protocol for Aphasia (MAAS) consists of:

-patient's general data: birth year, sex, education, place of residence; hospitalization; time of occurrence and cause of stroke; localization and lateralization;

-somatic information, such as: type of stroke, size and location of the lesion; CT / MRI; comorbidity;

-neuropsychological information: attention, concentration, verbal and non-verbal memory, semantic reasoning and executive functioning;

-psychosocial information: emotional disposition; motivation and psychological stressors;

-socio-economic status of patients: education, former profession, place of residence, social integration, hobby, etc.

The Clinical Protocol for Aphasia leads us to all the necessary diagnostic procedures, and these are in the first place:

- Linguistic assessments; the Clinical Protocol recommends the Boston Diagnostic Aphasia Examination, fluency tests, Token test;

- Neuropsychological examinations are conducted via neuropsychological diagnostic tests (forgeneral intellectualability, attention, and executive functions (TMT, Wisconsin Card Sorting Test), visuospatial and visuomotor functions, memory, behavioral tests and personality tests.

The value of the Clinical Protocol is its characteristic that interdisciplinarity is an imperative. The MAAS protocol includes five disciplines, i.e.the aphasia treatment team consists of five professionals. They are aphasiologist (dealing with clinical linguistics), neurologist (dealing with behavioral neurology), neuropsychologist, speech and language pathologist, and rehabilitation medicine consultant.The structure of involved professionals established by the MAAS protocol guarantees the achievement of the set goals of the treatment.

The MAAS Protocol is both diagnostic and prognostic. It is structured in five axes.

The first axis (or the vertical one) refers to linguistic information on the type and weight of aphasia, the nature of phonological and semantic disorders, and the quality of verbal communication. Linguistic assessment is crucial but not sufficient. The second axis refers to somatic information found by neurological/ neuroimaging, functional and diagnostic assessment. This axis provides information information on type of stroke, size and localization of the lesion, its localization, CT/ MRI and comorbidity (Basso, 1992).

Important neuropsychological information is obtained from the third axis of the protocol. These are pieces of information on attention, concentration, verbal and non-verbal memory, semantic judgment and executive functioning. The fourth axis of the Protocol provides psychosocial information about the psychoemotional disposition of patients with aphasia, motivation and psychological stressors that can have an impact on the effects of treatment.

Socio-economic data are obtained from the fifth axis of the Protocol and relate to the social circumstances of patients with aphasia such as education, occupation, housing, social environment (networking), hobbies, etc.

Upon completion of individual assessments by five professionals, the aphasia treatment team meets in order to analyze the obtained information and the overall MAAS profile. 
The MAAS profile indicates the direction and goals of the treatment. According to the ICF model (The International Classification of Functioning, Disability and Health), the three corresponding types of treatment can be distinguished: approach to leading disorder; functional approach and social approach.

The approach to leading disorder has the goal of restoring linguistic processes via cognitive-linguistic treatment, thus achieving the first principle of communication rehabilitation, remediation. Functional approach directs us to functional communication in everyday life. It may include teaching patients to use residual language skills as effectively as possible, and/or to use augmentative and alternative communication strategies such as gestures, use of communication books or other communication tools to compensate for linguistic deficit, thus achieving the principle of compensation and education.

Within the social approach, the focus is on life with the consequences of aphasia, taking into consideration that a patient with aphasia is at risk of social isolation (the principle of participation).

The social goal is accomplished by means of the constant support that a patient receives from the therapist during rehabilitation therapy. Participation is achieved through communication with family and friends, participation in self-help groups, other support groups and recreational activities.

The Aphasia team is both diagnostic and therapeutic in its character. It is also functional, while its particularity is flexibility and dynamism. Itsactivities are policlinic-dispensary and infirmary/hospital. Policlinic and dispensary work includes diagnostic and consultative protocol procedures, team meetings and some therapeutic procedures. Infirmary activity of the team members is the application and guidance of therapeutic procedures.

Since functionality is one of the Aphasia team's characteristics, it is not uncommon to involve other experts (psychiatrists, occupational therapists, experts in social rehabilitation, etc.)in both diagnostic process and treatment outcome (Lazić \& Čauševac, 2010).

\section{CONCLUSION}

The Clinical Protocol for Aphasia provides good guidance of adiagnostic process and a proper choice of treatment.It should be noted that although linguisticassessment is crucial, it proved to be insufficient for planned treatment of patients with aphasia.Only an interdisciplinary assessment can predict the outcome of a cognitive-linguistic treatment. Therefore, the attention should be paid to cognitive factors in the rehabilitation therapy of aphasia, taking in consideration the latest research from University of Pennsylvania, Department of Communication Sciences and Disorders, which argues that aphasia is not just a language disorder (Sandberg, 2017). This approach prevents patients and therapists from struggling with unsuccessful cognitive-linguistic therapy.

\section{REFERENCES}

Basso, A. (1992). Prognostic factors in aphasia. Aphasiology 6(4):337-48.

Čauševac, D. (2009). Rehabilitacija afazija. Savremeni tretman dece sa posebnim potrebama. Institut za psihofiziološke poremećaje i govornu patologiju „Prof.dr Cvetko Brajović“" zbornik radova. Beograd str. 25-29.

Čauševac, D., \& Oljača, V. (2012). Multiaksijalni afazija sistem (MAAS) - protocol za afazije. Prevencija, dijagnostika i tretman govorno-jezičkih poremećaja: Prvi Simpozijum logopeda Srbije. Nacionalni skup sa međunarodnim učešćem. Knjiga sažetaka. Ur. Vesna Borota i Neda Milošević. Divčibare: Udruženje logopeda Srbije,str. 68

Lazić, Lj., Čauševac, D., \& Jovičić, M. (2011): Depresija i karotidna bolest, VII Međunarodni.simpozij verbotonalnog.sistema „Čovjek i govor“ - 50 godina SUVAG-a. Knjiga sažetaka. Ur. Adinda Dulčić. Zagreb, str. 111

Van de Sandt-Koenderman, WM, van Harskamp, F., Duivenvoorden, HJ., Remerie, SC., van der Voort-Klees, YA., Wielaert, SM., Ribbers, GM., \& Visch-Brink, EG. (2008). MAAS (Multi-axial Aphasia System): realistic goal setting in aphasia rehabilitation. International Journal of Rehabilitation Research.31(4):314-20.

World Health Organization. (2001). International Classification of Functioning, Disability and Health: ICF. World Health Organization

Sandberg, CW. (2017). Hypoconnectivity of Resting-State Networks in Persons with Aphasia Compared with Healthy Age-Matched Adults. Frontiers in Human Neuroscience, 11.

Sandt-Koenderman, M. (2007). Crossroads in aphasia rehabilitation. Doctoral dissertation, Erasmus MC: University Medical Center Rotterdam 